\title{
Loucas ou modernas? Mulheres em revista (1920-1940)*
}

Cristiana Facchinetti** Carolina Carvalho***

\section{Resumo}

Este artigo propõe analisar, à luz da história cultural, as mudanças nas relações de gênero durante as décadas de 1920 a 1940, período de grande modernização do Rio de Janeiro. As fontes selecionadas para análise foram as vozes de médicos em periódicos científicos; cartas abertas de conselheiros em colunas sentimentais; e cartas de leitores de revistas de variedades. De novidade, o artigo sublinha o papel das "modernistas", uma das muitas categorias construídas no contexto da redefinição dos papéis sociais femininos que oscilavam entre representações de vanguarda e patologia.

Palavras-chave: Gênero, Modernização, Normalidade, Periódicos.

* Recebido em 21 de novembro de 2018, aceito em 29 de agosto de 2019. Es Este trabalho é fruto de pesquisa em APQ1 (FAPERJ) e de Iniciação Científica (PIBIC).

** Professora do Programa de Pós-Graduação em História das Ciências e da Saúde e Pesquisadora do Departamento de Pesquisa (DEPES), Casa de Oswaldo Cruz, Fundação Oswaldo Cruz, Rio de Janeiro,RJ, Brasil. cristianafac2011@gmail.com / https://orcid.org/0000-0003-4879-0307

*** Mestre em História das Ciências e da Saúde, Casa de Oswaldo Cruz, Fundação Oswaldo Cruz. Rio de Janeiro / RJ, Brasil. carolinaccarvalho@outlook.com / https://orcid.org/0000-0001-6088-2322 
Crazy or Modern? Women in Review (1920-1940)

\begin{abstract}
Through the lenses of cultural history, this article analyzes changes in gender relations during the decades of 1920 to 1940, a period of great modernization of Rio de Janeiro. The sources selected for analysis gave voice to scientific journals; open letters of sentimental columns; and readers' letters of magazines. Of novelty, the article underlines the role of the "modernists", one of the many categories constructed in the context of the redefinition of the feminine social roles that oscillated between vanguards and pathology's representations.
\end{abstract}

Keywords: Gender, Modernization, Normality, Journals. 


\section{Uma palavra sobre as revistas}

No início do século XX, a imprensa constituiu-se em um importante instrumento de divulgação da modernização das cidades brasileiras e, ao mesmo tempo, expressão desse processo. Mais do que os jornais diários, esses periódicos atuavam como "veículos de divulgação de valores, ideias e interesses", refletindo o novo retrato que se queria ter do Brasil (Martins; Luca, 2015:105). ${ }^{1}$ O novo ethos urbano carioca expressava-se nessas páginas por meio de carros, bondes elétricos, telefones, entre outras tecnologias.

O maior público das revistas de variedades era constituído pelas classes médias, que passaram a buscar o "juízo e a orientação dos homens de letras que preenchiam as redações", para negociarem o que era ser homem $e$ mulher modernos (Sevcenko, 1985:94). Esse cenário contribuiu para a centralidade da imprensa como divulgadora dos novos valores e comportamentos (Cohen, 2015). E, por essas revistas estarem "em perfeita sintonia com seu tempo" (Martins, 2001:565), este artigo tomou-as como fontes privilegiadas para a análise de "práticas pelas quais os indivíduos foram levados a prestar atenção a eles próprios, a se decifrar, a se reconhecer como sujeitos de desejo" (Foucault, 2012:11) no período.

\footnotetext{
1 Trabalhamos com dois grupos de revistas: revistas médico-mentais - Arquivos Brasileiros de Psiquiatria, Neurologia e Ciências Afins (ABP), Arquivos Brasileiros de Higiene Mental (ABHM) e Boletim de Eugenia (BE). E revistas de variedades - as selecionadas foram Jornal das Moças (JM), Vamos Ler! (VL!) e A Cigarra (AC). O primeiro grupo serviu para mapearmos os modelos e ideias propostos pelos médicos; o segundo grupo, das revistas de variedades, serviu para analisarmos o processo de circulação e apropriação - ou não - desses modelos.
} 


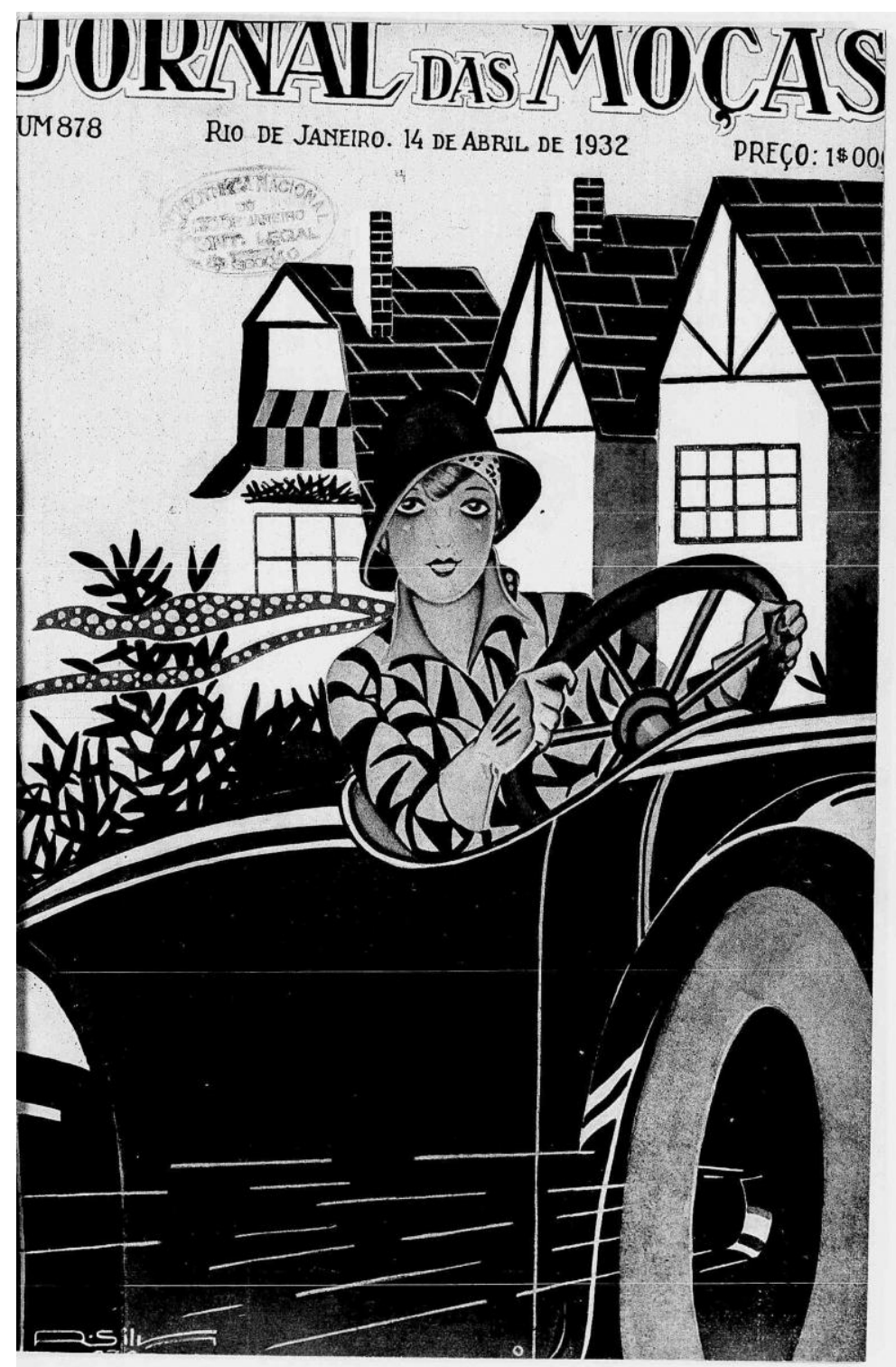

Imagem 1: Jornal das Moças, 14 de abril de 1932. Acervo: Arquivo Público de São Paulo 
Além dessas, os periódicos especializados cuja missão era orientar e normalizar a população urbana (Ferreira, 1999), a fim de criar o Normotypo Brasileiro (Brown, 1934), também informaram este artigo. O tom desses periódicos varia. Os Arquivos Brasileiros de Psiquiatria, Neurologia e Ciências Afins estavam mais interessados em descrever os processos patológicos dos indivíduos, enquanto os Arquivos Brasileiros de Higiene Mental e - Boletim de Eugenia voltavam-se principalmente para a população de "anormais", com ênfase na profilaxia. Todos estavam pautados por uma mesma formação discursiva acerca da saúde, da doença e dos papéis fixos para os gêneros, apoiados na anatomia e no determinismo da "natureza". Apesar de sua abrangência geográfica, esses periódicos eram de circulação restrita a um público especializado (Cupello, 2013) e com pequena variedade autoral, limitada a seus editores e correspondentes.

Ao reunir os dois grupos de impressos, quisemos acessar as diferentes vozes de especialistas, jornalistas e literatos que escreviam rotineiramente nesses meios de comunicação. Buscamos também a voz do público leitor por meio das cartas enviadas às diferentes seções. Aliás, as trocas entre leitores e/ou as cartas abertas de aconselhamento foram um dos critérios de seleção das fontes.

Apesar de assinadas por muitos leitores, algumas missivas podem ter sido escritas pelos editores como forma de induzir a participação do público alvo ou mesmo para aliciar certos comportamentos. Entretanto, este artigo toma como estratégia compreender a carta como produzida por um lugar de fala, pela função autor. Segundo Foucault (2009:274),

[...] para um discurso, o fato de que se possa dizer 'isso foi escrito por tal pessoa', ou 'tal pessoa é o autor disso', indica que [...] se trata de uma palavra que deve ser recebida de uma certa maneira e que deve, em uma cultura dada, receber um certo status. [...] A função autor é, portanto, característica do modo de existência, de circulação e de funcionamento de certos discursos no interior de uma sociedade. 
Deste modo, cada um desses lugares de fala - de leitores, especialistas e conselheiros das revistas - acaba por falar de um próprio modo de se apropriar, negociar e construir realidades (Chartier, 1990). É essa verdade da escrita, aquilo que ela revela acerca da realidade e dos modos de viver de homens e mulheres de uma época, bem como dos esforços de negociar novos hábitos como os de leitura, comportamento, trabalho e lazer, que tratamos neste artigo.

Nesse sentido, as cartas nos permitem acessar informações acerca desse público leitor, formado por homens e mulheres de todos os estados civis, de ampla faixa etária, com profissões $e$ níveis educacionais variados, frequentemente integrantes das classes médias urbanas. Mas, além disso, consideramos que ao serem escritas a um signatário, elas apresentam também um emissor, que se coloca ali como "inspetor de si" (Martins, 2011:67), dando transparência às representações de gênero $e$ às novas posições negociadas para homens e mulheres. O encontro dessas múltiplas vozes produz variações discursivas e semânticas quanto aos papéis de gênero, articulando novos arranjos e possibilidades para experiências e modos de ser. ${ }^{2}$ Finalmente, a escolha desse tipo de fonte contribui para demonstrar também a complexa rede de saberes e leituras acerca dos gêneros que resultam em representações de mulher ou, como seria mais adequado, de mulheres - sempre no plural.

\section{Quando o que era sólido se desmanchou sob os trilhos do bonde}

As reformas que modelaram o Rio de Janeiro da Belle Époque como vitrine do país frente ao estrangeiro (Motta, 2004) produziram efeitos diversos. "Toda uma nova série de hábitos, físicos, sensoriais e mentais" passaram a ser experimentados:

2 Quanto às temáticas abordadas pelos impressos, questões relacionadas ao homem e a mulher se revelaram o tema mais tratado pelos atores em suas escritas (56\%), especialmente nas revistas de variedades. Nelas, as mulheres (65\%) se destacam como tema de maior atenção quando em comparação com os homens $(35 \%)$. 
"esportes, danças, bebedeiras, tóxicos, estimulantes, competições, cinemas, shopping, desfiles de moda, chás, confeitarias, cervejaria" (Sevcenko, 1985:33). Assim, novas formas de viver entraram em cena, disputando com modelos tradicionais a orientação para um novo padrão de identidade nacional (Teixeira, 2005).

Como fenômeno histórico, essa nova chave de leitura do mundo não se tornou exclusiva, mas passou a competir com outros discursos sobre a "natureza humana" e seus limites para as transformações individuais e sociais modernas (Dias, 2015). Este conflito fez prevalecer incertezas e mal-estar. Afinal, homens $e$ mulheres haviam perdido a solidez de suas referências identitárias, que estavam, de fato, se desmanchando (Berman, 2007) sob os trilhos do bonde. Esse impacto pode ser bem avaliado no texto de S. Pinheiro, leitor premiado na seção "Dê a sua opinião... por 20\$000", publicada em Vamos Ler! (VL.):

Há indivíduos conservadores e saudosistas que se julgam com o direito de censurar os costumes da sociedade atual [...]. Andam [...] a dizer que já não há caráter, que a humanidade perdeu o sentido da moral [...]. O que está desaparecendo da face da terra é a hipocrisia, ela não serve no meio atual (VL!, 253, 1941:24).

Em resumo, as mudanças anunciavam o fim de um mundo capaz de autorregulação, no qual o "humano" era pensado a partir de uma essência unívoca; em seu lugar, propunha-se um universo aberto, em transformação contínua, marcado pelo pressuposto da "liberdade" (Birman, 1998). Uma das consequências disso foi o desencadeamento da (auto)reflexão sobre o que é ser moderno, em um novo tipo de análise do sujeito: sobre si e de si (Berger, Luckmann, 2012). Neste cenário, a ciência também representou uma voz - aliás, das mais imponentes - a responder pelos anseios de modernização e saúde. Com base nos novos referenciais científicos, a biomedicina $e$ suas especialidades passaram a discursar sobre os gêneros. 


\section{A mulher moderna e seus desvios}

Ao longo do século XIX, o olhar médico sobre o sexo acabou por essencializar a "natureza humana" e, a partir dela, o destino social dos indivíduos (Facchinetti, 2013). No caso das mulheres, construiu-se um discurso que reafirmava a maternidade como natural - isto é, delimitada pela essência biológica consagrando-a como única função social feminina e justificando sua exclusão do espaço público (Laqueur, 2001). Entretanto, esse destino era percebido como constantemente ameaçado, seja pelo instinto perverso, seja pelo livre-arbítrio. As mulheres eram definidas nas teses médicas por sua constituição lábil $e$, portanto, "mais sensíveis, mais impressionáveis, extremosas em tudo" (Firmino Junior, 1840 apud Rohden, 2001:109), o que as induziria à transgressão. No fim do século XIX, essa representação da vulnerabilidade passou a estar associada ao debate sobre as possibilidades de civilização nos trópicos (Dorlin, 2006). O evolucionismo e a hereditariedade potencializavam o perigo dos desvios biológicos e sexuais.

Além de comprometerem a saúde física, mental e moral dos indivíduos, as patologias daí decorrentes produziriam efeitos catastróficos sobre a prole, ameaçando a descendência e a nação em um processo de degradação social (Facchinetti; Muñoz, 2013). Assim, os médicos passaram a se preocupar ainda mais com o controle social a fim de garantir a "normalidade", o que implicava na manutenção dos papéis sociais para homens e mulheres segundo as funções sexuais.

No caso das mulheres, a atenção médica passou a englobar temas diversos, desde o trabalho feminino e a prostituição até a puericultura, a maternidade, a educação, a saúde pública, a imigração etc. Grande parte da argumentação justificava a maternidade e a vida no lar como funções essenciais da natureza feminina e anunciava os riscos de comportamentos antinaturais (Rohden, 2001). Repercutia, assim, no meio médico, o medo dos novos arranjos familiares e sociais da vida urbana, ainda mais 
diante das paulatinas transformações dos papéis de gênero (Cytrynowicz, 2000).

Com relação aos homens, o modelo de saúde masculina concentrava-se na figura do homem trabalhador, provedor e bom pai de família. Já para as mulheres, o trabalho fora de casa criaria uma familiaridade extremamente perigosa com o universo das ruas, e compunha, para alguns médicos, diferentes níveis de prostituição feminina, cuja classificação abrangia desde floristas, modistas, costureiras e mulheres de baixa condição social até aquelas que, de fato, trabalhavam como profissionais do sexo (Ferraz de Macedo apud Nunes, 1991).

Diversas cartas analisadas apoiavam plenamente essas interpretações. Leitoras, como Yara Maria, que, ao escrever para a seção "Os homens são assim..." de Vamos Ler!, afirmava que, embora o feminismo fosse "tão bonito, tão moderno", as mulheres sabiam "intimamente" que nasceram para serem "antes de tudo esposa e mãe adorada". Segundo ela, "a igualdade não deve[ria] existir", como garantia de felicidade das mulheres e desejo dos homens. Isso não teria a ver com a incapacidade feminina de realizar as mesmas funções que os homens; no entanto, competia às mulheres dar-lhes a "satisfação de nos proteger e endeusar" $e$, por isso, deveriam ser "mais femininas do que nunca" (VL!, 242, 1941:31).

$\mathrm{Na}$ década de 1920, a medicina mental ganhou nova roupagem teórica pela compreensão de que a doença (física, mental e/ou moral) era um "desvio constitucional", resultado de excessos ou faltas individuais (Dias, 2015:57). A educação, a moral $e$ os costumes, subordinados aos limites impostos pela biotipologia, funcionariam como elementos recalcadores - no sentido freudiano - dessas camadas profundas dos indivíduos, permitindo-lhes "disfarçar" suas tendências antissociais (Facchinetti, 2012).

A questão da constituição e de seus excessos era ainda mais notória no caso das mulheres brasileiras, pois a população mestiça fora frequentemente reconhecida como vítima de hiperestesia sexual (Carrara, 1997), marcada pela "impulsividade" e pela "fraca 
moralidade" (Nina Rodrigues apud Dias, 2015:79). Para esses médicos, fora de sua função biológica e social, essas mulheres se tornariam portadoras de "degeneração nervosa e mental", transformando-se em mulheres "más" (Austregésilo, 1938:109).

Quando observada a documentação médico-psiquiátrica do início do século $\mathrm{XX}$, ganha consistência a afirmação de que a "maldade" e a psicopatologia dela decorrente se manifestavam por meio ou por causa de uma rebeldia contra o destino natural da mulher. À falta de se conformarem com seu destino, essas mulheres "desobedientes", "irritáveis" e de "sexualidade e desejos excessivos", certamente fruto de uma "educação viciosa", insistiram em lutar contra a sua natureza e, por isso, adoeciam (Puech, 1907:352). Os documentos clínicos estão repletos de mulheres que "cometeram" excessos de leitura inadequada; de moças que tiveram instrução "em demasia" e, como resultado, ficaram desequilibradas entre uma "inteligência que prejudica" e a desobediência de seus "deveres sociais" (Roxo, 1906:130). As consequências mais danosas da rebeldia feminina seriam a inversão completa do seu papel natural: em vez de passivas, essas mulheres tendiam a querer "igualar-se ao homem" (Porto-Carrero, 1930:159).

De fato, sinais de transgressões do papel tradicional de mãe, esposa e dona de casa encontram-se às centenas nos documentos clínicos de mulheres internadas em asilos. É o caso de Bárbara de Jesus, uma viúva que "arrebatada de amor, abandona o seio de sua família para ir contrair núpcias com o eleito de seu coração", apesar de idosa (Engel, 2001:76).

Comportamentos como esses rompiam com os limites considerados dentro da normalidade pelos médicos. É o que se pode ver também no prontuário de Marília Ramos ${ }^{3}$, internada na Colônia Juliano Moreira, na década de 1940. Segundo as observações de seu prontuário, entre os sinais e sintomas de sua doença constam um ciúme excessivo do rapaz de quem gostava, além de um "temperamento alegre que a levava frequentemente a

${ }^{3}$ Os nomes de pacientes foram modificados para manter o anonimato. 
cantar "modinhas do mundo" (Prontuário, 1943). O "gênio irritável" e "agressivo" também constituíam sintomas que compunham a doença mental das moças (Prontuário, 1934).

$\mathrm{O}$ uso de roupas masculinas, assim como a busca de trabalhos não afeitos à essência feminina podiam também ser interpretados como sinal de moléstia mental. Clara Santana, empregada doméstica, foi internada no Hospital Nacional de Psicopatas após fugir da casa da patroa usando roupas masculinas, a fim de trabalhar num cinema paulista. Suas "excentricidades" e "vida irregular e incerta", assim como o vício em cocaína e morfina, atestavam, segundo os médicos, "um evidente abaixamento do senso moral e das faculdades éticas", marcados pelo "desembaraço" e pela "indiscrição", como resultado de "suas anormalidades afetivas, intelectuais e volitivas" (Laudo de Exame, 1924).

Mas era a sexualidade desregrada, dissociada da reprodução, o ponto de maior transgressão ressaltada pelos médicos. A liberação sem freios dos "instintos sexuais" comprovava a ausência de senso moral, que predispunha uma histérica grave à criminalidade, motivo pelo qual Maria, por exemplo, foi internada no asilo (Laudo de Exame... apud Engel, 2001:103). Do mesmo modo, a "grande exaltação da libido" e o vício da masturbação eram frequentemente enfatizados como evidência da degeneração e da doença mental femininas (Ficha de Observação, 1940).

Além da internação compulsória, indicava-se como posologia profilática a conservação dos dois sexos "paralelamente distintos, exercendo cada um o seu papel" e "completando-se para a perpetuação da humanidade" (Kehl, 1925:90). Para isso, a mulher brasileira deveria ser reeducada de modo a formar lares perfeitos e fecundos para a pátria (Kehl, 1930). Isso seria atingido por meio de uma educação científica, capaz de apoiar a reprodução saudável como "verdadeira significação do casamento" e combater as doenças venéreas e a prostituição. As mulheres, "responsáveis pela reprodução" e, ao mesmo tempo, 
"mais frágeis às vontades do sexo", constituíam o grande alvo das medidas disciplinadoras do "instinto sexual" (Kehl, 1930:2).

Os médicos não eram os únicos que apoiavam a continência sexual ou que se preocupavam com a natureza feminina. Esse argumento também se encontra nas narrativas de leitoras de revistas. É o exemplo de Es Re Is, 19 anos, que, ao escrever para Vamos Ler!, manifestava sua preocupação - e certa indignação - com os avanços feministas em prol da conquista do ensino superior e do trabalho. Para a jovem leitora, "devemos ser instruídas, sim. Mas o suficiente para a educação de nossos filhos". Tais limites seriam determinados pela própria essência humana, uma vez que os homens "estão muito acima de nós, mulheres, $e$ nós [...] sempre seremos fracas" (VL!, 248, 1941:50).

Os médicos preconizavam medidas rígidas advindas da higiene mental e da eugenia para exorcizarem certos "fantasmas da emancipação" (Porto-Carrero, 1933:90), que teimavam em ameaçar o futuro da nação. Se era verdade que a mulher tinha "o cérebro idêntico ao do homem", seu sexo era naturalmente "desigual" ao masculino (Kehl, 1925:95). A educação científica faria da esposa moderna o braço-direito da higiene mental, em prol da modernização da sociedade:

quando cada mulher [...] tiver confiança em si e sentir o dever da espécie, de ser mãe, quando a escolha do esposo puder ser consciente, por uma educação sexual que não a deixe corar ante $\mathrm{o}$ ato natural com que os pais a engendraram, quando uma educação física lhe demonstrar que muitos dos seus impulsos podem ser sublimados, sem fantasias românticas e sem misticismo neurosante, então a servidão da mulher será um fato histórico, a tentar pesquisas de ciência, pois que a esposa $e$ a serva serão conceitos antagônicos (Porto-Carrero, 1933:90).

Aí está o modelo "normal" de mulher, "dona de seu lar e mãe exemplar" ( $A$ Cigarra (AC), 97, 1942:98), esclarecida, consciente e educada, colaboradora do marido, da ciência e da pátria, quando a serviço de sua prole. Muitas das missivistas que 
encontramos nas revistas reafirmavam o lugar "natural" da mulher. De fato, quando acompanhamos as (auto)definições das leitoras das revistas, vemos desfiar um rosário de qualidades femininas tradicionais. Em suas cartas, as leitoras consideram que a mulher é "a mais perfeita obra de Deus" ( $A C, 418,1932: 32)$; "sublime e adorável" ( $A C, 364,1930)$; "amorosa" ( $A C, 94,1942: 98)$; "anjo tutelar" (JM, 862, 1931:46); cheia de "bondade e mimo" ( $A C$, 119, 1944:92). Essas mulheres interpretavam a maternidade como uma missão "sagrada e santa" (JM, 855, 1931:44), "uma lei imposta pela natureza e à qual nenhuma criatura procura fugir" ( $V L, 244,1941: 50)$. Tais mulheres representariam ainda grande "consolo" para os seus, como "mártires" que eram, capazes de grande "senso de justiça" e de "sacrifícios" por sua prole $(A C, 381$, 1930:7). Aqueles que compartilhavam desse ideal reforçavam ainda que a sociedade estaria em sério risco de degradação, justamente por causa da sombra da emancipação (VL!, 241, 1941:16).

O casamento constituía outra peça-chave para a manutenção da normalidade, desde que fosse programado segundo princípios eugênicos. Ao circunscrever os instintos sexuais no círculo familiar e submeter o casal ao olhar clínico por via dos exames pré-nupciais, "o casamento se encrustou na encruzilhada entre os comportamentos sexuais dos indivíduos $e$ a transformação da sociedade" (Facchinetti, 2013:36). O papel da "esposa-mãe" e sua missão biológica ocupavam posição central nesse arranjo, já que era ela a responsável pela educação das gerações futuras, saudáveis e modernas (Freire, 2006). Segundo essa perspectiva, os papéis femininos tradicionais seriam a garantia da preservação da saúde das mulheres e do bom funcionamento da sociedade.

No entanto, é possível observar que o perfil de "mulher normal" vinha ganhando novas nuances pelos médicos. Se a autonomia de mulheres era, no século XIX, marca inequívoca de sua insanidade, paulatinamente emergem nas primeiras décadas do século XX personagens que conseguem escapar à ação psiquiátrica e ao destino comum da moléstia mental. $\mathrm{O}$ caso de 
Elza, diagnosticada pelos médicos como portadora de "degeneração atípica", é exemplar dessa passagem. Segundo Muñoz, ela não delirava, não alucinava, não era agressiva e nem ameaçara física ou mentalmente aqueles com quem convivia. Fora internada no Hospital Nacional pela polícia a pedido do cônjuge, após tê-lo abandonado em troca de seu ex-sócio. Enquanto a polícia e o marido consideraram que só a loucura justificava o comportamento de Elza, parte da opinião pública, incluindo advogados e juristas, discordava que ela sofresse das faculdades mentais. Como resultado, Elza foi liberada do asilo por habeas corpus oito dias após sua internação (Muñoz, 2010).

Zizi Papillon é outra mulher com um comportamento considerado desviante que, apesar de ter uma passagem pelo asilo, não ficou internada. A bailarina francesa fez um escândalo público em sua passagem pelo Rio de Janeiro, "tornou-se louca furiosa", ao não ser correspondida por seu amor: "chorava, ria, arrancava os cabelos e chamava pelo ingrato, cujo nome não cessava de proferir a todo momento". Zizi foi encaminhada para o Hospital Nacional, mas saiu no dia seguinte, "alegre $e$ completamente curada" da crise da qual fora vítima. Segundo os jornais, o jovem que provocara seu acesso de loucura havia se rendido aos seus encantos (A Rua, 1915:180).

Assim, ao longo das primeiras décadas do século $\mathrm{XX}$, a missão de "regeneração nacional" da medicina mental se tornou cada vez mais sistematizada e, ao mesmo tempo, mais difícil. Apesar dos esforços para "melhorar as condições de saúde física $e$ mental de nossa gente" (Moreira, 1925:109), os "desvios" de comportamento feminino eram cada vez mais comuns e não estavam circunscritos apenas às mulheres internadas nos asilos: segundo o eugenista Renato Kehl, as desviantes representavam uma "grande porcentagem entre as mulheres, sobretudo nas metrópoles". A profunda e crescente "deterioração social" vinha ameaçando a estabilidade psíquica feminina $e$, por conseguinte, o futuro da nação (Kehl, 1925:88). E é do questionamento mais geral acerca das fronteiras de gênero que trataremos a seguir. 


\section{Mulheres modernas, mas "normais"}

A moral sexual hegemônica das décadas anteriores prevalecia - as leis, as referências religiosas, os modelos de família $e$ os ideais médicos o apontam. Em meio à troca de correspondência, é possível demonstrar a contínua valorização de um perfil tradicional de mulher, como Andréa, descrita pela conselheira sentimental como muito exigente, de grande valor moral, possuidora de "uma única missão verdadeira na alma: ser mãe e companheira ideal" do homem ( $A C, 119,1944)$; ou Esperança, louvada como modelar por seu excessivo pudor $(A C$, 364, 1930). Entretanto, a insistência com que os médicos reafirmavam os perfis tradicionais tanto para mulheres, quanto para homens, permite entrever que a modernização conservadora de hábitos e costumes enfrentava resistências a esses valores, tal como o público leitor expressava em suas cartas.

Assim, é possível vislumbrar que o discurso médico sobre a "mulher normal", longe de se estabilizar, continuou a escorregar em meio a debates e contradições. A vigilância médica e sua legitimidade cresciam e ganhavam maior importância social, por meio das novas estratégias de "defesa da raça", propugnadas pela higiene mental e pela eugenia (Souza, 2006). Porém, esse discurso não se infiltrava de maneira homogênea nas entranhas da cidade, disputando espaço com outros enunciados.

Nas revistas de variedades, é frequente a tentativa dos conselheiros de pautarem comportamentos e hábitos moralmente corretos e/ou saudáveis para cada gênero. Mas, ao lidarem com os sujeitos em suas diferenças, vemos deslizar o que os médicos tomavam como sólidos conceitos de verdade acerca da normalidade e da patologia. Nessas trocas de correspondência se estabeleciam as negociações e as novas fronteiras - mais alargadas - para a normalidade, em um espaço de sociabilidade incerto, no qual não se sabia mais, a priori, até onde podia ir uma mulher na condução de um flerte ou de um namoro, se podia ou não usar maiô, ir à praia com o namorado, ficar a sós com o médico; se deveria trabalhar e, caso sim, em quais ofícios; se deveria ou não 
estudar, por quantas horas, o que podia ler etc. Nesse diálogo, os conselheiros tendem a substituir a tradicional educação parental: "Há coisas que os pais sabem e não querem informar às filhas, por motivos de escrúpulos paternais" (AC, 108, 1943:99).

Afinal, como manter intacta a concepção médica ou a tradição moral para condutas femininas quando mesmo as "boas moças de família" não estavam mais escondidas da esfera pública, por trás das venezianas (Cupello, 2013)? Antes, circulavam pelos bondes, liam romances, iam a festas, teatros e cinemas, fumavam, usavam calças compridas e cabelos curtos, estudavam $e$ trabalhavam fora. Se no passado a mulher normal era sempre recatada e pudica, nos "dias hodiernos" era considerada normal também a mulher "honesta" e de "caráter probo", "fiel ao seu marido e que é, apesar disso, coquette", arrastando "atrás de si uma chama de desejo" (VL!, 308, 1941:37), já que considerava-se que aquele era "o próprio narcisismo do instinto" feminino ( $V L !$, 248, 1941:52).

Como insistir na vida doméstica, quando o maior modelo civilizatório do país no período - a Europa - empregava suas mulheres nos mais diferentes postos de trabalho durante a guerra, modificando seus discursos sobre os perigos do trabalho para as mulheres? $\mathrm{O}$ que fazer com os movimentos sufragistas, que cresciam a olhos vistos? Através da imprensa reverberavam as notícias sobre as conquistas femininas, como a mobilização das mulheres nos esforços de guerra $e$ sua luta por representatividade na esfera pública (Cytrynowicz, 2000).

Especificamente no que diz respeito ao trabalho externo, as opiniões divergiam. Para grande parte dos médicos, o desejo feminino de trabalhar fora continuava a representar uma "calamidade mental" extremamente perniciosa para a saúde da mulher, da família e, em uma escala ainda maior, da própria nação (Porto-Carrero, 1930:90). A vontade de ser[em] "puramente companheira[s] de trabalho" do homem representava uma "mentira" capaz de tornar as mulheres "rancorosas" $e$ "machonas", afetando sua sexualidade e seu destino natural (Porto-Carrero, 1933a:86). 
No entanto, também surgiram no período alguns especialistas mais entusiastas com os avanços femininos, que afirmavam que a mulher vinha se mostrando "progressivamente colaboradora da civilização brasileira no ensino, na política, na ciência, nas letras e na administração" (Austregésilo, 1938:s/p). Argumentavam ainda que diversas atividades poderiam ser executadas pelas mulheres. Além de profissões relacionadas a extensões da maternidade como a pedagogia, a educação, a enfermagem, a medicina, sobretudo a pediatria e a assistência social, de mesmo modo constituíam possibilidades de triunfo para "mulheres normais" as atividades artísticas, "nas formas que sublimam a masturbação feminina com o emprego dos dedos instrumentos de corda, máquinas de escrever e de estatística, o bordado e a costura". Tarefas "maravilhosamente" executadas pela mulher (Porto-Carrero, 1933a:85). Essa nova perspectiva, mais flexível, acompanhava as mudanças sociais, permitindo novas roupagens para a dedicação aos filhos e à família, e abrindo espaço para os cuidados com o corpo, com a aparência e com o intelecto, convivendo ao lado das concepções mais tradicionais.

\begin{abstract}
É hoje licito [à mulher] escolher, preferir, dedicar-se, enfim, ao trabalho que mais convém ao seu temperamento $e$ vocação [...]. E, então, desde a máquina de escrever ao balcão das lojas, da operária às mesas telefônicas, da simples arquivista à cabeceira dos enfermos, dos trabalhos do campo à arte culinária, do microscópio à tribuna parlamentar, a mulher substitui o homem, auxilia-o na luta pela vida, ameaçando-o até mesmo de uma competição mais viva, tida e havida até agora como "privilégios do sexo forte" (Austregésilo, 1938:s/p).
\end{abstract}

Entretanto, essas conquistas devem ser encaradas com cautela. Além das ressalvas feitas tanto por médicos quanto pelas próprias mulheres sobre qual ofício era mais adequado à mulher, muitas vezes o trabalho feminino continuava a ser compreendido como prejudicial, capaz de corromper as relações entre homens $e$ mulheres. 
Diante do espectro da emancipação, algumas leitoras, como F.T.H., acusavam as mulheres que trabalhavam fora - as "outras" - de responsáveis pela crise nos relacionamentos:

Nota-se hoje uma acentuada tendência por parte das mulheres [...] em se ocuparem na vida com trabalhos dantes reservados apenas aos homens. [...] o certo é que muitas vezes saem-se melhor, conseguindo uma situação mais vantajosa que a de seus colegas do sexo masculino. [...] Há uma consequência que não deve ser esquecida: os homens [...] não podem, tão depressa como desejavam, constituir família e daí, essa crise de maridos, que não é tanto devido à pouca inclinação deles para o matrimônio, como se poderia supor, mas sim por falta dos necessários recursos financeiros, o que decorre certamente da concorrência que as mulheres lhes fazem nos empregos. Por aí se vê que o resultado que elas obtêm abandonando o lar pelo escritório [...] é antes um passo para o aumento progressivo das solteironas e dos celibatários (VL!, 244, 1941:16).

Como parte fundamental do processo de emancipação das mulheres, a entrada no mercado de trabalho era vista muitas vezes como uma ameaça de virilização. A contadora Alice Brandão garantia em sua carta que o curso de contabilidade - e o trabalho que ganhou por causa dele - não foi capaz de destruir seu "caráter feminino", nem havia tirado dela "o interesse pelos assuntos da mulher". Ela garantia

que sob a blusa da mulher que trabalha ainda pulsa o mesmo coração feminino, com suas eternas frivolidades que nós mesmas e os homens também achamos adoráveis (VL!, 241, 1941:44).

Outra consequência do trabalho feminino, discutida por grande parte das senhoras, era o abandono do lar e da educação dos filhos, assim como a falência do casamento, já que "o êxito do matrimônio está 80\% nas mãos da esposa" ( $A C, 129,1944: 107)$. 
Novamente, algumas mulheres falavam em defesa do novo espaço social conquistado, afirmando que trabalhar não significava abrir mão de seu destino natural. Diziam então que, apesar de sentirem "um sincero entusiasmo pelos progressos da mulher" nesses novos tempos e de estudarem, lerem, praticarem esportes e trabalharem, "depois de um dia de mulher moderna" buscavam refúgio em seu "mundo espiritual", isto é, "na amizade e no apoio de um homem" (VL!, 242, 1941:30). Essas eram mulheres como Maria Luiza, uma das colunistas em Vamos Ler!, que afirmava que o trabalho não a impedia de possuir um "lar perfeitamente constituído dentro dos padrões da sociedade atual $e$ do Código Civil". Ao rebater as acusações de um leitor sobre a incapacidade de ser "ao mesmo tempo mãe, esposa e trabalhar em igualdade de condições com os homens", Maria Luiza também informava sobre os direitos trabalhistas em favor das mulheres:

Ficarei em licença [maternidade] durante três meses, sabe por quê? Consulte as leis trabalhistas. Você proclama que a mulher nasceu para ser mãe [...]. Mas se isto é uma lei imposta pela natureza e da qual nenhuma criatura procura fugir... Que tem a maternidade a ver com a nossa independência moral e material? (VL!, 244, 1941:50).

Deste modo, apesar dos limites impostos pela conjuntura, a emancipação avançava, desconstruindo o modelo de mulher tradicional ao confrontar o lugar social naturalmente atribuído às mulheres. Em consequência, houve uma ampliação das franjas de normalidade feminina no período, ainda que os modelos tradicionais não tenham deixado de existir. 

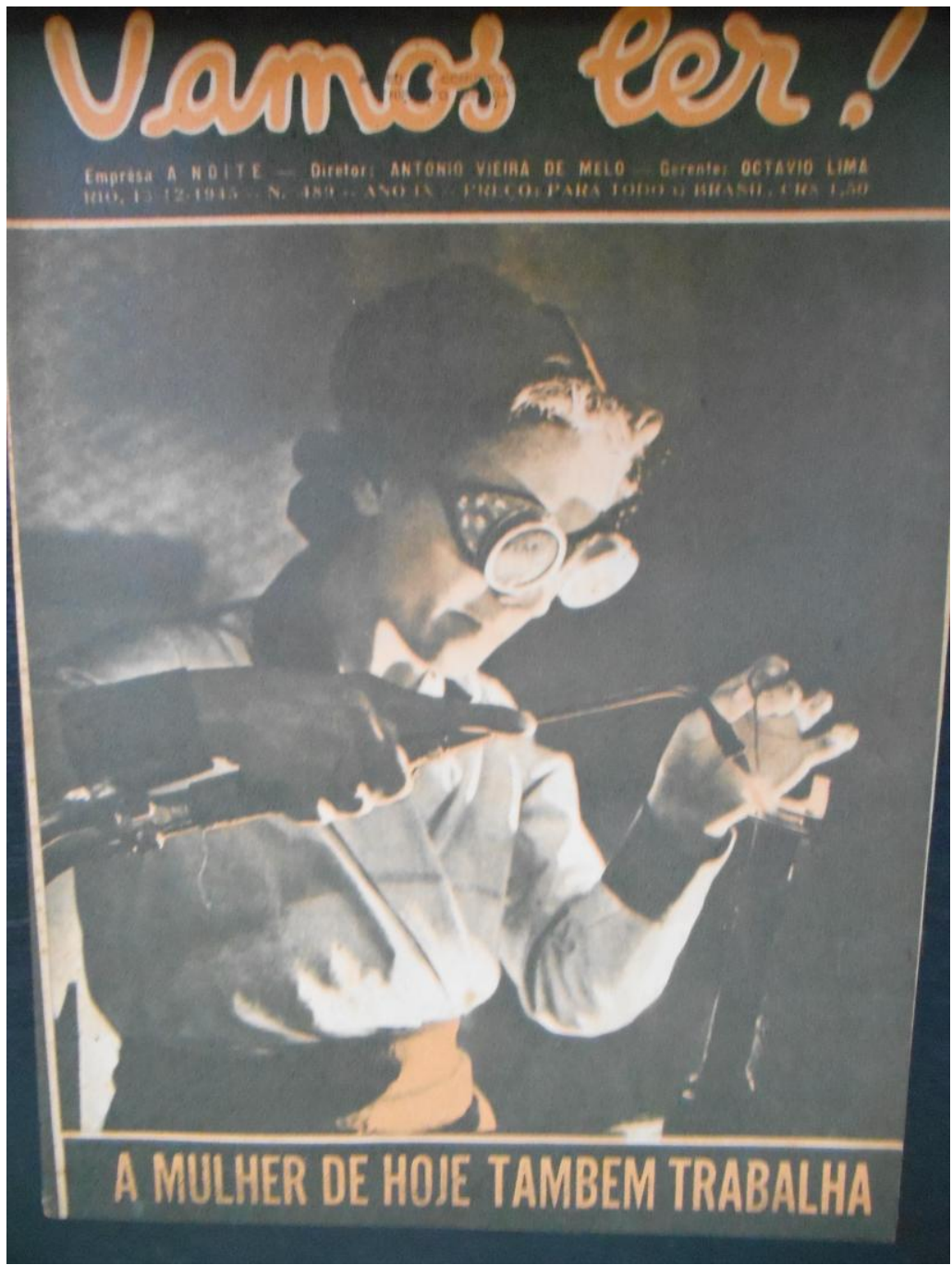

Imagem 2: VL!, 489, 13/12/1945. Acervo: Fundação Biblioteca Nacional. 


\section{Do destino natural à mulher emancipada: as modernistas}

A nova mulher "normal", apesar de trabalhar fora, devia atentar sempre para a "discrição". Em resposta aos anseios das próprias mulheres, os conselheiros das revistas orientavam essas moças trabalhadoras acerca dos limites na emancipação política $e$ econômica, a fim de dissipar quaisquer dúvidas quanto à moral $e$ à honestidade delas, inibindo impressões de que seriam "levianas", "levadas" ou "namoradeiras" ( $A C, 420,1932: 4)$.

A preocupação com a aparência feminina era frequente nas páginas das revistas, nas seções de moda que divulgavam as tendências europeias, sobretudo francesas, ou nas matérias $e$ propagandas sobre cuidados com o corpo, não só para fins de coqueteria, mas também de saúde, revelando hábitos da mulher moderna e sua preocupação crescente "em embelezar as formas do corpo", por meio de ginástica, alimentação e "até uma rigorosa limitação nas diversões" (VL!, 17, 1936:25). Ser uma mulher moderna, portanto, passava a significar também a possibilidade de transfigurar a própria essência por meio da modelagem do corpo (Rago, 2004); implicava vestir-se adequadamente ao estilo de vida moderno e dedicar-se ao asseio pessoal em prol da higiene da "mulher dinâmica, que trabalhava fora" (Kobayashi, 2012:135).

Mas não era apenas o trabalho externo em repartições públicas, escolas, hospitais e outros espaços que garantia às mulheres novas experiências de sociabilidade. Os encontros sociais em cafés e bailes, os recitais de poesia, as audições musicais, as partidas de jogos, também preenchiam as páginas das revistas, que tratavam da sofisticação dos anfitrióes pelos comes $e$ bebes ou pelas novidades da vida boêmia que redesenhava uma elite fora dos esquadros modelares, além de oferecer cultura para a massa (Velloso, 2013).

Estampadas nas revistas, encontram-se mulheres glamourosas, de cabelos curtos à la garçonne, calças compridas e cigarros nas mãos, que recheavam as revistas com escândalos, amantes, separações, desquites e vários casamentos, assim como viagens e hábitos que arruinavam a utopia médica (cf. Amaral, 
2004; Pontes, 2006). Junto a elas surgiam novos espaços de entretenimento: filmes, peças de teatro, literatura e artes de vanguarda, que apontavam para certa subversão dos parâmetros sociais mais tradicionais, desafiando as normas e insurgindo-se contra certas convenções, tanto nos meios mais ricos da cidade quanto na boemia carioca (Velloso, 1996). E as leitoras se entusiasmavam:

De fato, o salão do Palace está sempre cheio, principalmente de senhoras, porque, como se sabe, há mulheres que se sentem irresistivelmente fascinadas pelas coisas esquisitas e horríveis... Mas esperemos que Tarsila [do Amaral] reflita e, arrependida de esbanjar o talento que dizem possuir, volte a pintar só quadros belos, tão belos como a sua pessoa! (D’Aron, 1929:2).

Assim, o período em que as mulheres buscavam participar cada vez mais ativamente na vida pública (Duarte, 2003) foi também propício para o florescimento de um novo tipo de mulheres, que se espelhavam em artistas de vanguarda $e$ membros de uma elite a quem tudo parecia permitido. Ecoando os comportamentos liberais dos artistas de vanguarda, outras mulheres, trabalhadoras em sua maioria, foram se posicionando de forma mais crítica frente às imposições normativas de seus papéis sociais.

Essas mulheres eram chamadas pelas revistas de época de modernistas. Entre elas, o desejo de emancipação estava na ordem do dia. Ainda que o trabalho fora do lar fosse criticado por boa parte das leitoras, havia muitas a favor do trabalho externo, $e$ mesmo alguns dos missivistas homens destacavam com certo otimismo o fato de as mulheres modernas estarem em toda parte, "desde o lugar mais modesto às mais complexas modalidades do trabalho, mesmo os de caráter essencialmente intelectual $e$ científico" (VL!, 13, 1936:42). Essa posição é também endossada por alguns colunistas das revistas, que consideravam positivas as mais novas discussões sobre os temas. Chegavam a afirmar que 
as experiências modernas da fisiologia mostram que as funções femininas em nada podem privar seu organismo de uma adaptação razoável aos trabalhos até então consagrados ao homem (VL!, 4, 1936:35).

Nas seções de aconselhamento, o trabalho também passava a ser indicado como uma solução moderna para as mulheres. Assim, Emília, que se autointitulava modernista e "primeira mulher divorciada numa família de costumes patriarcais", recebeu o seguinte conselho ao se queixar da incompreensão de seus pais:

Não se ponha a lamuriar: trate de arranjar um emprego [...], seja de que natureza for [...]. Então, longe da atmosfera dos seus, vivendo dignamente pelo próprio trabalho, terá reconquistado a emancipação pecuniária, que traz em si todas as emancipações, menos a emancipação moral, porque esta é uma questão de foro íntimo [...]. Compreendo perfeitamente a posição incômoda em que se acha. A senhora pertence ao número das precursoras, e não há nada mais desagradável nesse mundo do que ser precursor (VL!, 379, 1943:50).

É possível notar ainda uma mudança de expectativa em termos de escolaridade feminina, que se tornava uma exigência, pois "uma mulher ignorante é um martírio para quem convive com ela!" (VL!, 238, 1941:43). Assim, apesar da heterogeneidade de opiniões a respeito do trabalho e da educação da mulher, a vida fora do lar foi paulatinamente se tornando uma realidade, uma opção, ainda que o casamento continuasse a ser o plano mais importante para grande parte das moças.

Em um tempo em que o feminismo avançava em todo o mundo, nada mais adequado. Entretanto, diferente das feministas que Martha Freire (2006) estudou, e que reivindicavam o direito de voto para avançarem nos direitos da educação feminina associada à maternidade, as "modernistas" incomodavam mais. Em primeiro lugar, porque reivindicavam a igualdade entre os sexos. Em diálogo com médicos como Austregésilo e Porto- 
Carrero, que afirmavam que a emancipação da mulher poderia suscitar doenças nervosas, alguns leitores, como o Sr. Junior de Maia, chegaram a censurar Vamos Ler!, quando a revista abriu uma seção para tratar da emancipação feminina. Segundo ele, o tema era um verdadeiro perigo para a "mentalidade feminina brasileira", porque tais ideias "sugestionam as jovens com opiniões pessimistas, capazes de levá-las ao suicídio ou à loucura" (VL!, 246, 1941:40). O desejo de emanciparem-se, portanto, não dizia exatamente respeito ao fato de as mulheres passarem a seguir certas tendências modernas de trabalharem fora, instruíremse adequadamente ou equilibrarem-se entre o mercado de trabalho e serem boas donas de casa. Ser modernista implicava a insistência de certas "ultramodernices", como independência, autossuficiência e direitos iguais ( $A C, 381,1930: 9)$.

Sempre que tratam das "modernistas", os leitores homens das revistas as definiam como representantes da antiessência do feminino, já que não teriam "nem delicadeza de maneiras, nem gestos medidos, nem sorrisos em que a castidade fosse uma auréola" ( $A C, 419,1932: 2)$. Apesar de valorizarem "as grandes $e$ nobres conquistas femininas", criticavam "certas liberdades" que faziam com que essas mulheres se tornassem verdadeiras "palhaças" ou "atrizes de quarta ordem", e desconsiderassem a "sua grande missão na Terra": a maternidade (AC, 419, 1932:2). É possível perceber nas revistas que o grande perigo associado às tendências chamadas "modernistas", bastante extravagantes, era o despertar do desejo pela "igualdade dos sexos na sublimação pelo trabalho" e na "liberdade da conjunção sexual" (Porto-Carrero, 1930:159).

Ao reprovarem "a liberdade de gestos, o gosto pelos esportes, a finura da conversação e de pensamento, tidos como excessivos", os leitores nos informam quem a tal modernista é: "sport-woman, é eleitora, é amante dos bailes e dos flirts, só não é boa dona-de-casa" ( $A C, 364,1930: \mathrm{s} / \mathrm{p})$. Essas mulheres eram também tachadas de "inimiga[s] dos homens" e fadadas a serem "um fracasso" como esposas ( $A C, 380,1930: 6)$. 
A crítica advinda de certos argumentos modernos, mas conservadores, entrava em disputa com o discurso de personagens que, por sua vez, valorizavam o fato de que a "mulher brasileira" moderna não se deixava "dominar" ao reivindicar seus direitos (AC, 418, 1932:32). Para esses defensores da emancipação, a mulher havia tomado "consciência do seu valor individual $e$ social" através do trabalho e da afirmação de sua personalidade. Se no passado a mulher havia sido submissa e oprimida, nos tempos modernos "se assegura[va] uma vida livre por seus esforços próprios e pelo exercício de suas aptidões". Assim, a "emancipação de espírito" era valorizada como "a mais bela conquista que a mulher deve ao trabalho" (AC, 418, 1932:32-33). Diziam então que "o que revolta os homens não é que a mulher trabalhe (se a pobre sempre trabalhou), mas que trabalhe em igualdade de condições com eles" (VL!, 244, 1941:50). As mais radicais apontavam que pensar era a maior vingança das mulheres, a fim de mostrar aos homens que "também temos cérebro e não apenas coração ou corpo", e que "também analisamos os seus atos e os seus sentimentos e que também temos uma opinião formada a respeito deles" (VL!, 235, 1941:50).

Ainda que não correspondessem à maioria das mulheres representadas nas revistas, esse tipo de mulheres participava ativamente dos debates. Algumas delas juntavam suas vozes às feministas para afirmarem que apenas desejavam romper com a subordinação aos homens, que "desde os tempos mais remotos" teriam negado "direitos e educação" às mulheres por medo de que "pudéssemos nos tornar concorrentes aos direitos da vida". Atribuíam à vaidade e ao egoísmo dos homens as "injustiças sociais feitas às mulheres" (VL!, 241, 1941:50). Para superá-las, propunham um permanente "programa de luta pela emancipação feminina", para que o homem passasse a ver "que a única desigualdade que existe entre eles é a diversidade dos sexos" (VL!, 244, 1941:41).

Deste modo, o comportamento modernista colaborava assim entendiam - para que fosse possível atingir um novo patamar moderno, quando a mulher iria "rebenta[r] os grilhões do 
cativeiro e galga[r] brilhantemente o lugar a que tem direito" ( $V L !$, 69, 1937:49). Entretanto, ampliando as sonoridades desse coral dissonante, outras vozes alertavam para o perigo de tamanho modernismo:

Já fui ultramoderna [...]. As mulheres que se empenham em viver uma vida estritamente do século $\mathrm{XX}$ acabam por perder um pouco do próprio encanto. Sei disso por experiência própria. Tive um namorado que me estimava sobre todas as coisas. [...] Naquele tempo eu era excessivamente moderna [...] Muitas vezes paguei a conta $e$ achava isso muito natural, quando a despesa ia além das suas posses. Hoje esse rapaz não me cumprimenta sequer [...]. Aconselho a todas as jovens que desejam conservar um romance prestar muita atenção nesse ponto [...]. Nada encanta mais um homem do que sentir que há alguém dependendo dele. As mulheres que resolvem tudo por si $e$ que não pedem nunca a opinião de seu noivo ou marido, estão arriscando uma boa parcela de felicidade própria [...]. As mulheres expeditas demais, que nunca se acham em apuros, nem mesmo imaginariamente, são muito cortejadas, mas raramente se casam (VL!, 130, 1939:75).

\section{Considerações finais}

Tanto as revistas médicas quanto as de variedades permitiram confirmar a existência de discursos diversos de atores que integravam a imprensa brasileira entre as décadas de 1920 e 1940. Estes muitas vezes mobilizavam argumentos médicos e psicológicos, além de discursos advindos da moral tradicional e religiosa, e de um sexismo científico para fundamentarem a diferença entre os sexos e os papéis "naturais" de gênero. Outras vezes, acercavam-se do conhecimento científico para defenderem justamente o contrário, isto é, a igualdade entre homens e mulheres.

Ao permitirem acesso às visões de mundo de um público leitor leigo, as trocas de correspondências dão maior visibilidade à crise de identidade tão característica dos tempos modernos, 
trazendo à tona a diversidade das experiências daqueles que vivenciavam os novos modos de ser e de viver urbanos no país. Se elas revelam a presença viva de ideias tradicionais na construção de modelos identitários para os gêneros, evidenciam também os conflitos que anunciavam as mudanças nos papéis sociais de gênero.

Para além da pluralidade dos tipos urbanos que se tornavam expressão dos novos costumes, as revistas expressam diferentes lugares de enunciação discursiva, contribuindo para dar nuances às interpretações de comportamentos. Pudemos, assim, identificar disputas e negociações pela hegemonia discursiva na construção do ideal de mulher e de homem modernos, em que a medicina mental, ainda que efetivamente presente, era apenas um dos muitos fios que compunham a rede de representações de gênero no período.

As tensões íntimas dos indivíduos nesse mundo em trânsito constante foram demonstradas por meio de casos concretos avaliados pelos diferentes atores presentes nas revistas. Os motivos de suas angústias, aspirações e lutas, assim como as respostas encontradas, sobretudo por meio de aconselhamento, demonstram certa complexidade e fluidez das representações de saúde e doença. Ao mesmo tempo, tais relatos revelam as possibilidades de negociação discursiva frente a temas como emancipação, igualdade de direitos e trabalho. As mulheres, além de alvo do discurso médico e personagens de destaque no processo de modernização social, surgem nas revistas como partícipes da produção de discursos sobre as mulheres modernas no processo de construção identitária. A multiplicidade de vozes e lugares que marcam esse cenário viabilizou o surgimento de alternativas a modelos tradicionais femininos, dentre eles as "modernistas", identificadas por sua excentricidade à norma, mas ainda assim presentes como possibilidade no horizonte da mulher moderna.

Nesse contexto histórico, em que novas possibilidades se apresentavam às mulheres, elas buscavam não apenas novos referenciais ideológicos na construção de suas identidades, mas 
também construíam redes que lhes permitiam versarem $e$ negociarem novas subjetividades. Assim, no que diz respeito às "modernistas", o que as difere daquelas internadas $e$ diagnosticadas como loucas no mesmo período é a sua capacidade de articular e acionar essas redes de práticas de si $e$ representações discursivas a seu favor. Desse modo, ainda que frequentemente se veja sublinhado seu caráter radical ou extravagante, as modernistas conseguiram manter-se em meio às redes de sociabilidade que as sustentavam $e$ as tornavam respeitadas e dotadas de relativo status. Em contrapartida, outras mulheres que se separavam, tinham amantes, abandonavam filhos, não cuidavam da casa ou queriam viajar sozinhas eram interditadas no Hospício Nacional de Alienados. Tal variação dentro de um mesmo período e num mesmo círculo de saberes revela que, nas análises sobre as negociações e debates acerca dos gêneros, devem-se incluir também considerações sobre o caráter contingente e contextual dos diagnósticos médicos, das práticas institucionais para alienados $e$ da produção de identidades doentes.

Por fim, o processo de apropriação relativa e parcial dos saberes científicos pelos discursos do público leitor leigo permite refutar a ideia de um controle biopolítico absoluto no processo de redefinição dos papéis de gênero. Isto, porém, não recusa a existência de esforços profiláticos de higienização social com vistas a garantir saúde e desenvolvimento da nação, em disputa com outros discursos de verdade.

Por meio das fontes apresentadas, foi possível conhecer formas de apropriação das novas ideias que circulavam pelas revistas e o modo como impactavam de maneira diversificada a produção dos sujeitos concretos e da cultura urbana do período. Assim, no jogo das representações, as mulheres desempenharam não apenas o papel de objeto de discurso, mas também participaram como agentes, produzindo versões próprias e novas construções identitárias, em um processo de negociação das representações de mundo e de si. 


\section{Referências bibliográficas}

\section{Fontes primárias}

A CIGARRA. São Paulo, 1924-1944.

AustregéSILO, Antônio. Perfil da mulher brasileira: esboço acerca do feminismo no Brasil. 2a Ed. Rio de Janeiro, Editora Guanabara, 1938.

BRown, Isaac. O Normotypo Brasileiro. Rio de Janeiro, Guanabara, 1934.

D'ARON, Arly. A arte infantil de Tarsila. Gazeta de Notícias, Rio de Janeiro, 4 ago. 1929, n. 183, p.2.

FiCHA De OBSERVAÇÃo. Colônia Juliano Moreira, 1940. (IMASJM) In: FIOCRUZ. Base de dados Psi-COC (BDPC). Rio de Janeiro. Coord., Cristiana Facchinetti, 2008.

JORNAL DAS MOÇAS. Rio de Janeiro, 1931.

KEHL, Renato. Como escolher uma boa esposa. Rio de Janeiro, Livraria Francisco Alves, 1925.

KEHL, Renato. Crescei-vos e multiplicai-vos. Boletim de Eugenia, ano II, n. 22, 1930, p.2.

Laudo De Exame De Sanidade Mental. Manicômio Judiciário, 1924 (HCTPHC) In: FIOCRUZ. BDPC. Rio de Janeiro. Coord., Cristiana Facchinetti, 2008.

MOREIRA, Juliano. A seleção individual de imigrantes no programa da higiene mental. Arquivos Brasileiros de Higiene Mental, ano I, s.n., 1925, pp.109-115.

O RomAnCE da Zizi Papillon. A Rua, n. 180, 3 jul. 1915, p.2.

PORTO-CARRERO, Julio. O exame pré-nupcial como fator eugênico. Arquivos Brasileiros de Higiene Mental, ano VI, n. 2, 1933, pp.90.

Porto-CARRERo, Julio. O sexo e a cultura. Arquivos Brasileiros de Higiene Mental, ano III, n. 5, 1930, pp.157-166.

Porto-Carrero, Julio. Psicanálise de uma civilização. Rio de Janeiro, Editora Guanabara; Waissman, Koogan, 1933a. 
PRONTUÁRIO. Colônia Juliano Moreira, 1943 (IMASJM). In: FIOCRUZ, BDPC, Rio de Janeiro. Coord., Cristiana Facchinetti, 2008.

PRONTUÁRIO. Hospital Nacional de Alienados. Seção Esquirol, 1934 (IMASNS). In: FIOCRUZ. BDPC. Rio de Janeiro. Coord., Cristiana Facchinetti, 2008.

PUECH, Luiz M. de Rezende. Ginecologia e alienação mental. Arquivos Brasileiros de Psiquiatria, Neurologia e Ciências Afins, ano III, n. 2, 1907, pp.352-353.

Roxo, Henrique. Dos estados mentais nas grandes nevroses. Arquivos Brasileiros de Psiquiatria, Neurologia e Ciências Afins, ano II, n. 2, 1906, pp.139-148.

VAMOS LER!! Rio de Janeiro, 1936-1943.

\section{Fontes secundárias}

Amaral, Maria Adelaide. Tarsila. São Paulo, Globo, 2004.

BERGER, Peter; LuCKMANn, Thomas. Modernidade, pluralismo e crise de sentido: a orientação do homem moderno. $3^{\mathrm{a}}$ ed. Petrópolis: Vozes, 2012.

BERMAN, Marshall. Tudo que é sólido desmancha no ar. a aventura da modernidade. São Paulo, Companhia das Letras, 2007.

BIRMAN, Joel. O mal-estar na modernidade e a psicanálise: A psicanálise à prova do social. Physis, vol. 8, n. 1, Rio de Janeiro, 1998, pp.123144.

CARRARA, Sérgio. A geopolítica simbólica da sífilis: um ensaio de antropologia histórica. História, Ciências, Saúde-Manguinhos, vol. III, n. 3, Rio de Janeiro, nov. 1996-fev. 1997, pp.391-408.

CHARTIER, Roger. A história cultural: entre práticas e representações. Rio de Janeiro: Difel/Bertrand Brasil, 1990.

COHEN, Ilka Stern. Diversificação e segmentação dos impressos. In: MARTINS, Ana Luiza; LUCA, Tania Regina de (org.). História da imprensa no Brasil. $2^{\mathrm{a}}$ ed. São Paulo, Contexto, 2015, pp.103-130.

CuPELlo, Priscila Céspede. A mulher (a)normal: representações do feminino em periódicos científicos e revistas leigas na cidade do Rio de Janeiro (1925-1933). Dissertação (Mestrado em História das 
Ciências e da Saúde), Casa de Oswaldo Cruz/Fiocruz, Rio de Janeiro, 2013.

CYTRYNOWICZ, Roney. A escassez das empregadas e a mulher fora de lugar. In: CYTRYNOWICZ, Roney. Guerra sem guerra: a mobilização e o cotidiano em São Paulo durante a Segunda Guerra Mundial. São Paulo, Edusp, 2000, pp.121-134.

DIAS, Allister. Arquivos de Ciências, Crimes e Loucuras: Heitor Carrilho e o debate criminológico do Rio de Janeiro entre as décadas de 1920 e 1940. Tese (Doutorado em História das Ciências e da Saúde), Casa de Oswaldo Cruz/Fiocruz, Rio de Janeiro, 2015.

Dorlin, Elsa. La matrice de la race. Généalogie sexuelle et coloniale de la nation française. Paris, La Découverte, 2006.

DuARTE, Constância Lima. Feminismo e literatura no Brasil. Estudos Avançados, vol. 17, n. 49, São Paulo, dez. 2003, pp.151-172.

EnGEL, Magali Gouveia. Os delírios da razão: médicos, loucos e hospícios (Rio de Janeiro, 1830-1930). Rio de Janeiro, Editora Fiocruz, 2001.

FACCHINETTI, Cristiana; MuÑOZ, Pedro Felipe Neves de. Emil Kraepelin na ciência psiquiátrica do Rio de Janeiro, 1903-1933. História, Ciência, Saúde-Manguinhos, vol. 20, n. 1, Rio de Janeiro, mar. 2013, pp.239-262.

FACCHINETTI, Cristiana. A doença do prazer. Revista de História da Biblioteca Nacional, vol. 93, Rio de Janeiro, 2013, pp.32-34.

FACCHINETTI, Cristiana. Normal, anormal, patológico: representações de gênero no Estado Novo. Relatório final de pesquisa (APQ1-FAPERJ). Rio de Janeiro, 2014.

FACCHINETTI, Cristiana. Psicanálise para brasileiros: história de sua circulação e sua apropriação no entreguerras. Culturas Psi, Buenos Aires / Santiago do Chile, vol. 0, n. 1, p. 45-62.

FERREIRA, Luiz Otávio. Os periódicos médicos e a invenção de uma agenda sanitária para o Brasil. História, Ciências, Saúde-Manguinhos, vol. 6, n. 2, Rio de Janeiro, 1999, pp.331-551.

Foucault, Michel. O que é um autor? In: Foucault, Michel. Ditos e Escritos: estética, literatura e pintura, música e cinema. $2^{\text {a }} \mathrm{Ed}$., Vol. III, Rio de Janeiro,, Forense Universitária, 2009, pp.82-118. [1969]. 
FouCAUlt, Michel. A História da Sexualidade II - o uso dos prazeres. Rio de Janeiro, Graal, 2012.

FREIRE, Maria Martha de Luna. Mulheres, mães e médicos: discurso maternalista em revistas femininas. (Rio de Janeiro e São Paulo, década de 1920). Tese (História das Ciências e da Saúde), Casa de Oswaldo Cruz/Fiocruz, Rio de Janeiro, 2006.

KOBAYASHI, Elizabete Mayumy. Higiene e consumo: novas sensibilidades para um Brasil Moderno (décadas de 1940 a 1960). Tese (Doutorado em História das Ciências e da Saúde), Casa de Oswaldo Cruz/Fiocruz, Rio de Janeiro, 2012.

LAQUEUR, Thomas. Inventando o sexo: corpo e gênero dos gregos a Freud. Rio de Janeiro, Relume Dumará, 2001.

Martins, Ana Luiza; LuCA, Tania Regina de (org.). História da imprensa no Brasil. $2^{a}$ ed. São Paulo, Contexto, 2015.

MARTINS, Ana Luiza. Revistas em revista. São Paulo, Fapesp; Edusp; Imprensa oficial, 2001.

MARTINS, Vanessa Gandra Dutra. Reflexão sobre a escrita epistolar como fonte histórica a partir da contribuição da teoria da literatura. Revista Língua e Literatura, vol. 13, n. 20, Frederico Westphalen, ago. 2011, p. 1-216.

MotTA, Marly. Rio, cidade-capital. Rio de Janeiro, Jorge Zahar Editor, 2004.

MuÑOZ, Pedro Felipe Neves de. Degeneração atípica: uma incursão ao arquivo de Elza. Dissertação (Mestrado em História das Ciências e da Saúde), Casa de Oswaldo Cruz/Fiocruz, Rio de Janeiro, 2010.

NunES, Silvia Alexim. A medicina social e a questão feminina. Physis, vol. 1, n. 1, Rio de Janeiro, 1991, pp.49-76.

PONTES, Heloisa. Vida e obra de uma menina nada comportada: Pagu e o suplemento Literário do Diário de São Paulo. cadernos pagu (26), Campinas-SP, Núcleo de Estudos de Gênero-Pagu/Unicamp, jan/jun. 2006, pp.431-442.

RAGO, Margareth. A invenção do cotidiano na metrópole: sociabilidade e lazer em São Paulo, 1900-1950. In: PORTA, Paula (org.). História da 
cidade de São Paulo, vol. 3, São Paulo, Paz e Terra, 2004, pp.387435.

ROHDEN, Fabíola. Uma ciência da diferença: sexo e gênero na medicina da mulher. Rio de Janeiro, Editora Fiocruz, 2001.

SEVCENKO, Nicolau. Literatura como missão: tensões sociais e criação cultural na Primeira República. São Paulo, Brasiliense, 1985.

SoUZA, Vanderlei Sebastião de. A política biológica como projeto: a "eugenia negativa" e a construção da nacionalidade na trajetória de Renato Kehl (1917-1932). Dissertação (Mestrado em História das Ciências e da Saúde), Casa de Oswaldo Cruz/Fiocruz, Rio de Janeiro, 2006.

TEIXEIRA, Nincia Cecília Ribas Borges. Imagens literárias urbanas: Machado de Assis e Lima Barreto, o Rio de Janeiro escrito a quatro mãos. Tese (Doutorado em Letras), Faculdade de Ciências e Letras, UNESP, Assis, 2005.

Velloso, Monica Pimenta. Haute Bicherie no Rio de Janeiro: reconfigurações do olhar iluminista no imaginário franco brasileiro. In: FLECHET, Anais; COMPAGNON, Olivier (org.). Os franceses não tomam banho? Imagens e imaginário da França no Brasil (século XIX e XX). Rio de Janeiro, Fundação Casa de Rui Barbosa, 2013, pp.12-24.

Velloso, Monica Pimenta. Modernismo no Rio de Janeiro: turunas e quixotes. Rio de Janeiro, FGV, 1996. 